\title{
Recensión del libro Belleza y responsabilidad. El arte y la virtud política según Jacques Maritain, de Gennaro G. Curcio ${ }^{1}$
}

\author{
Recension of the book Beauty and Responsibility. Art and Political \\ Virtue According to Jacques Maritain, by Gennaro G. Curcio
}

\author{
Carlos Daniel Lasa ${ }^{2}$
}

Citar: Lasa, D. (2020). Recensión del libro Belleza y responsabilidad. El arte y la virtud política según Facques Maritain, de Gennaro G. Curcio. Cuadernos Universitarios, 13, pp. 111-113.

Recibido: marzo 2020

Aceptado: setiembre 2020

Reseña descriptivo-crítica
No son muchos, dentro del pensamiento metafísico en general, los que centren su reflexión filosófica en el trascendental belleza. Siempre se privilegia la consideración de los demás trascendentales del ser: la unidad, la verdad o el bien.

El profesor Gennaro Curcio, en su escrito titulado Belleza y responsabilidad. El arte y la virtud política según Facques Maritain, propone reconstruir la vida política actual a partir del trascendental belleza.

La tesis del profesor Curcio es absolutamente original. En este sentido, se vale de la meditación maritainiana acerca de la belleza y de la obra que el artista produce a la luz de esa misma belleza. A partir de allí, establece una relación intrínseca con la tarea del político. Este último, al igual que el artista, también

${ }^{1}$ Curcio, G. G. (2019). Belleza y responsabilidad. El arte y la virtud política según Facques Maritain. Salta, EUCASA, 278 pp.

${ }^{2}$ Doctor en Filosofía por la Universidad Católica de Córdoba (1993). Docente de Filosofía, Ética y Filosofía del Derecho en la Universidad Nacional de Villa María, la Universidad Católica de Córdoba y la Universidad Católica de Salta. Es también profesor del Doctorado en Pedagogía (UNVM), de la Maestría en Investigación Educativa (UCCOR) y del Diplomado en Políticas Públicas (UCOM, Asunción, Paraguay). Es Investigador independiente en el Consejo Nacional de Investigaciones Científicas y Técnicas de la Argentina (CONICET). Investigador categoría 1 en el Programa Nacional de Incentivos del Ministerio de Educación de la República Argentina. Autor de 9 libros, entre ellos: El hombre a-lógico o la finalidad de la educación actual (1996), Hombre, metafísica y sentido, Por una educación que eduque; Algunas reflexiones en torno al problema educativo actual; ¿Qué es el peronismo? Una mirada transpolítica. Autor, también, de más de 70 artículos de su especialidad en revistas de filosofía del país y del extranjero. Es integrante del Comité Científico de Revistas de Filosofía del país y del extranjero. Académico de Número de la Academia del Plata, Sección Córdoba. 
está destinado a producir el esplendor de la verdad (belleza) en la vida de la ciudad.

El capítulo primero del libro, titulado «La belleza para Maritain en el debate contemporáneo» (pp. 25-77), se ocupa, precisamente, del concepto que los Maritain (Jacques y su esposa Raissa) tuvieron de belleza, si bien Curcio relee esta concepción de los Maritain a la luz del debate actual. Más concretamente, lo ilumina a partir de las críticas que algunos contemporáneos de Maritain le formularon a su posición sobre la belleza y el arte.

De este modo, Curcio recrea las críticas de Benedetto Croce, Armando Carlini y Vittorio Stella. Luego señala posiciones más afines a las de Maritian, cuales son las de Umberto Eco, Elisa Oberti y Cosimo Campanelli.

El segundo capítulo se titula «Los Maritain y la experiencia del pluralismo de la belleza» (pp. 78-141). Aquí el autor analiza, a partir del epistolario y de las relaciones de los Maritain con los artistas (poetas, músicos, etc.), las cuestiones en torno al tema. No está ausente, en esta consideración, el nexo entre arte y lógica y la posición del filósofo francés respecto de los surrealistas.

En el capítulo tercero, «La esencia interior entre arte y conocimiento» (pp. 143-167), Curcio muestra la relación adecuada que debiera existir entre la poesía, el hombre y las cosas. En este punto, se ocupa de mostrar cómo el arte es una virtud del intelecto práctico. En este sentido, el arte hace posible que la acción sea realmente efectiva, extendiéndose su eficacia a la vida de la polis.

El capítulo cuarto lleva por título «La virtud de la prudencia y del arte: una relación conyugal» (pp. 169-195). Aquí se estudia cómo el arte, en cuanto perteneciente al dominio del saber práctico, no tiene como objetivo demostrar la verdad. Este cometido sería propio del intelecto especulativo. El arte, de suyo, debe manifestar el esplendor, la belleza.

E1 capítulo quinto, «La virtud del arte: instrumento pedagógico más auténtico» (pp. 197-215), constituye, junto con el sexto, la plasmación de la tesis del profesor Curcio. En este apartado pretende mostrar de qué manera la virtud del arte se erige en dadora de forma humana («segunda naturaleza»). Y esta nueva forma, consecuentemente, es fermento de la vida buena en la sociedad política.

Permítasenos referir un pasaje del libro que estamos recensionando: $« \mathrm{E} 1$ artista tiene su relevancia social, debe ser un ejemplo para la comunidad porque contribuye a la formación de opiniones, a tomar conciencia y a dar vida a modas diferentes que seguramente nos llevan hacia la verdad» (p. 209). Como podemos apreciar, la belleza, que es esplendor de la verdad del ser, ordena el alma del artista. Asimismo, también es capaz de organizar la vida de la polis.

Finalmente, en el capítulo sexto (217-267), el autor ahonda en el tema de la responsabilidad tanto del artista como del político. Los dos, en cuanto artistas, debieran plasmar la belleza, contemplada in interiore, en su objeto propio y específico. En la obra de arte, el artista; en la organización justa de la polis, el político.

La belleza no solo es capaz de transformar la vida personal elevándola a la perfección, sino también la vida de los hombres que viven en una sociedad. Tanto el artista como el político deben dar cuenta del esfuerzo personal que hayan puesto en conformar sus vidas según el orden intrínseco de la belleza. Y no solo eso. También deben colaborar en la conformación de la materia inerte y de la materia libre de acuerdo con la belleza que es esplendor de la verdad. Materia inerte, en el caso del arte; materia libre, en lo que atañe a la organización de la polis.

La tarea de producir belleza, tanto por parte del artista como del político, exige, como 
condición necesaria, vivir conforme a ella. Ex- piritual. Sobre este hombre plasmado por las presa Curcio: «La persona se vuelve artífice y virtudes emerge la belleza de la política, por centro alrededor del cual debe girar la política, cuanto la libertad responsable logra echar raípuesto que una buena política es fruto sola- ces, convirtiéndose en lugar fundamental de mente de una "bella" formación humana y es- las elecciones y de las acciones» (p. 267). 